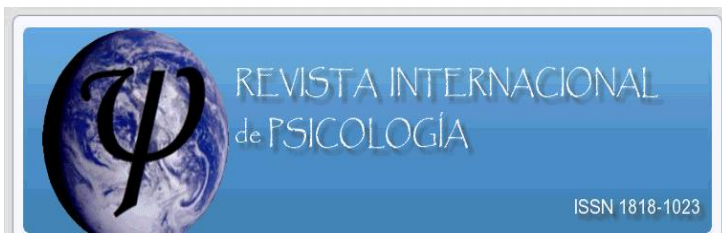

\title{
ESTUDIOS DE TURISMO Y PSICOLOGIA: génesis del placer en el psicoanálisis freudiano clásico.
}

Lic. Maximiliano Korstanje $\mathrm{e}^{1}$

\section{RESUMEN}

En el siguiente trabajo nos proponemos demostrar teleológicamente, los diferentes tratamientos que la psicología ha hecho sobre el placer y sobre todo los aportes y limitaciones que el psicoanálisis demuestra en la materia. El placer se configura de esta forma como aquella descarga que nivela la perturbación sufrida por los instintos de vida (Eros) y de muerte (Thanatos) en conjunción con la excitación exógena. En consecuencia, el principio de la transferencia explica el desplazamiento (turístico) como una forma de equilibrio psíquico.

\section{PALABRAS CLAVES}

Psicología - Psicoanálisis - Placer - Turismo

\begin{abstract}
In this work we intend to demonstrate the different treatments which the Psychology has made about the pleasure as well as the contributions or limitations that the psychoanalysis demonstrates in the matter. The pleasure is configured like a discharge generated by the encounter between the instincts of life (Eros) and of death (Thanatos) in conjunction with the exogenous excitement. In consequence, the principle of the transfer explains the displacement (tourist) like a form of psychic balance.
\end{abstract}

\section{KEY WORDS}

Psychology - Psychoanalysis - Pleasure - Tourism.

\section{INTRODUCCIÓN}

La etimología de la palabra placer, nos lleva al latín antiguo cuya significación es gustar (placere). Esta raíz, ha quedado impregnada aún en algunas lenguas indo-europeas actuales (sobre todo las romances) ${ }^{2}$. Pero la significación que se le da al término en nuestros días, parece ser polisémica.

\footnotetext{
${ }^{1}$ Pontificia Universidad Católica Argentina. Correo electrónico: maxikorstanje@ hotmail.com

${ }^{2}$ En italiano por ejemplo se denomina, piacere. En holandés plezier, en portugues prazer, en francés plaisir, en inglés pleasure y en español placer entre otros.
} 
Es posible, que el placer y el turismo estén (en algún punto) estrechamente emparentados, y también hay indicios que por medio de éste se pueda diferenciar al turismo de la migración propiamente dicha. Ambos fenómenos voluntarios, que conllevan una dinámica diferente. Por otro lado, divertirse también adquiere un sentido contrario ya que proviene de divertere, la cual a su vez connota "separarse, hacerse a un lado, apartarse". Este segundo término, parece tener más que ver con el turismo (en su dinámica) moderno que el placer en sí mismo, empero existe cierto placer en divertirse y en desplazarse. ¿Pero como se forma?

Las preguntas que inmediatamente (aquî) surgen son ¿Qué es el placer?, ¿se puede comprender este término sin su contrario el no placer?, ¿como juegan ambos dentro de la estructura psíquica?, ¿es el placer el elemento que fundamenta y genera ese desplazamiento al que llamamos turístico?.

Por ese motivo, el siguiente ensayo se predispone a realizar un tratamiento exhaustivo para definir que es el placer y como éste interactúa entre el ego y su capacidad adaptativa.

A nuestro modo de ver (aún con su tendencia filo-genética) creemos que el psicoanálisis es una de las disciplinas que mejor a estudiado el tema hasta el momento y paradójicamente es una las teorías menos utilizadas por los investigadores para explicar el factor lúdico y su influencia en el desplazamiento turístico. Una tarea, que a primera vista, puede parecer sencilla pero que hasta ahora no ha sido realizada. ${ }^{3}$

\section{Desarrollo académico (la personalidad y el placer)}

El turismo se ha convertido en los últimos años en un fenómeno que crece a cada instante. No obstante, se requiere aún de teoría (y mucha) sobre todo con respecto a las motivaciones psicológicas que se ponen en funcionamiento a la hora de emprender un viaje. Fernandez Fuster nos explica que "si consideramos la existencia del Turismo como fenómeno visto desde la vertiente individual, particular, del turista, el concepto de la psicología se mostrará como necesario para la determinación de las motivaciones del viaje, las preferencias por los lugares elegidos, los cuandos, comos y porque. La

\footnotetext{
${ }^{3}$ El propio lenguaje utilizado por la teoría psicoanalítica no parece ser simple de comprender.
} 
vertiente individualista nos lleva derechos a una Psicología del Turista”. (Fernandez Fuster, 1967:18)

En su trabajo, Turismo y Transporte, Blanco sostiene "podemos afirmar que en general todo el mundo es turista potencial. Para dar el paso definitivo y poder convertirse en turista, es necesario que se cumplan dos condiciones: voluntad y posibilidad. Hablar de voluntad es referirse al deseo o curiosidad por viajar y conocer otros lugares, otras gentes, otras culturas.” (Blanco, 2001:15)

En efecto, el deseo o su análogo el placer parece influir en forma directa sobre la decisión de desplazarse y en consecuencia de hacer turismo. Si bien una de las primeras disciplinas interesadas en el placer fue la psicología, y sobre todo la asociacionista, la posición en su tratamiento sobre la conciencia y la acción estaba equivocada.

Uno de los pasajes escritos (hace un tiempo) por el padre del interaccionismo simbólico, hacen expresa referencia al hecho de que "toda la doctrina de la psicología que sigue a Hume fue predominantemente asociacionista. Dados ciertos estados de conciencia, se suponía que eran mantenidos agrupados por otros elementos similares. Entre estos elementos se encontraban los del placer y el dolor. Relacionada con este atomismo de estados concientes asociados, había una psicología de la acción basada en la asociación del placer y el dolor con ciertas otras sensaciones y experiencia. La doctrina de la asociación era la doctrina psicológica dominante: trataba la experiencia estática antes que la dinámica” (Mead, 1999:64).

En otras palabras, las sensaciones estáticas como el olor, el gusto y el color pueden no estar relacionados directamente con los estados de placer y displacer, sino más bien con la construcción procesual de la persona por medio de la comunicación, y cuya póstuma expresión se hallan en el juego y el deporte. (Mead, 1999:180-195)

Estos dos mecanismos asociados, se encuentran presentes en el proceso de socialización y en consecuencia internalizan en el sujeto las normas grupales y la posición del "otro" en él mismo (a través de la constitución del "mî" y su accionar sobre el “yo"). Es decir, que en la competencia deportiva, el sujeto sabe (concientemente) no sólo que su acción 
repercute en el juego sino además que re-conoce todas las acciones posibles de los “otros” en él.

Asimismo, para Mead, tanto el juego como el deporte representan la evidencia de que el ser se forma por medio de la interacción social.

En este contexto, aunque el autor no hace expresa referencia, tanto el placer y el displacer no funcionan como elementos individuales sino que se desarrollan en cuanto a otros externos pero presentes en la conciencia del sujeto. Aquello que le causa placer al sujeto, no necesariamente le cause placer a los demás también; sin embargo, para que el influjo pueda ser aprehendido debe estar internalizado como una posible forma de placer o displacer. Cuando alguien compra un regalo para otra persona, intuye que éste será de su agrado.

El placer que siente en regalarlo, no está vinculado al yo propio, sino a la internalización de aquello que le causa placer al otro; y viceversa. Pero para que este hecho social tan complejo se de, debe existir por parte de ambos una construcción común con respecto a lo que genera placer y displacer en ambos. En efecto, tanto el placer como su contralor, son parte de los estados afectivos primarios del agente cuya función es controlar la conducta y dirigir la acción en cuanto a "otros" quienes también se dirigen hacia el "yo". Sin embargo, no sabemos el motivo por el cual Mead no se preocupa por definir que se entiende por placer en toda su obra. Entonces, ¿qué es el placer?.

En ocasiones, algunos confunden al placer con la sensación; y si bien es posible que se parezcan, caben algunos reparos antes de continuar. Para responder ontológicamente a la pregunta planteada, recurriremos al filósofo alemán Immanuel Kant. Para éste, en todo sujeto, existe una tensión entre el placer y el bien (deber). La moral culmina con la idea del bien. A su vez, el deber es una figura a priori de todo juicio (moral). La voluntad de hacer el bien es lo único que nos somete a la ley moral (Vleeschauwer, en Belaval, 2002:210-222). La moral, por lo tanto, es interna a cada uno.

La primera distinción que elabora Kant sobre el conocimiento se versa sobre conocimiento puro y empírico. El primer término se desprende de los conocimientos $a$ 
priori el cual se distingue por ser independiente de la experiencia. Por ejemplo, podríamos estimar que en cierta temporada y para determinado hotel no encontraríamos ningún tipo de disponibilidad aun cuando no nos hemos percatado de ello en base a nuestra experiencia. ¿Pero como llega Kant a la sensación como construcción analítica?.

Pues, por medio del juego entre percepción e intuición. En los axiomas de la intuición, Kant hace expresa referencia a este tema cuando señala "no puedo representarme una línea, por pequeña que sea, sin trazarla con el pensamiento, es decir sin producir todas sus partes poco a poco, desde un punto, y así dibujar esa intuición. Lo mismo ocurre con el tiempo, por corto que sea. Pienso en el tránsito sucesivo de un momento a otro, por donde, mediante todas las partes del tiempo y su audición, prodúcese finalmente una determinada magnitud" (Kant, 2004:143)

En el momento en que la intuición se adelanta a la percepción, se está en presencia de la sensación (realitas phaenomenon), la cuál no es otra cosa que una forma de conocimiento empírico a priori. Pero Kant, sabe que la sensación no va de las partes al todo (como en el caso del tiempo o la música) sino que se halla en la aprehensión y no por medio de la síntesis. De esta forma, concluye que toda sensación posee magnitud intensiva (segundo axioma). Esta meditación, le otorga tanto al placer como al dolor (displacer) una intensidad y en consecuencia un punto de equilibrio. Ambos podrían distinguirse en grados con respecto a un objeto percibido e incluso (aquí el aporte del autor) revertirse. Por ejemplo, nuestro deseo de viajar a Córdoba para Navidad puede ir disminuyendo o aumentando su intensidad hasta llegar a 0 (vacío) y desaparecer o hasta hacerse contrario y transformarse en aversión. Esta idea estará presente en Freud cuando elabore su tesis sobre el placer y el principio de realidad.

Pero también lo interesante el pensamiento kantiano radica en la intuición como herramienta de conocimiento. Sin él, todo conocimiento es imposible. Mejor dicho, todo conocimiento (empírico) es sensible (ya que es dado al sujeto) y no racional.

Entonces, ¿estaríamos en condiciones de afirmar que el placer es un elemento clave en la conformación de la personalidad y ésta una forma de adaptarse al entorno?. 
Desde un marco conceptual análogo al interaccionismo y la filosofía kantiana, el canadiense Eric Berne, desarrolló a principios de los 60 un modelo que según él explicaba las diferentes etapas en las que se constituía el ego. A diferencia de las edades del hombre de Eriksson (2000) para quien las etapas eran procesuales, en Berne estos estadios del "yo" coexistían en la personalidad adulta entre sí. Según el autor, nuestro aparato psíquico se construye en tres manifestaciones: padre, adulto y niño (PAN).

Cada una de estas fases, muestra características específicas. En la experiencia interna, el padre está vinculado a las normas, el cuidado, y nuestra certeza sobre la forma de conducirse en el mundo. La dinámica de esta esfera es netamente normativa premia por un lado, y castiga por el otro. Luego, viene el adulto, quien según Berne tiene la pauta de adaptación al medio y de respuesta según parámetros objetivos y analíticos. En esta etapa, el sujeto se comporta de acuerdo a su conveniencia. Por último, el estadio del niño hace referencia a todos esos sentimientos inductivos que nos permiten disfrutar, experimentar placer a veces en forma maníaca, distanciándonos de la estructura normativa del grupo. (Berne, 1974)

Aplicando los alcances de Berne a nuestro trabajo, podemos señalar que cada estadio guarda también semejanza con la forma de comportamiento que se manifiesta en la esfera laboral y en la del placer. En efecto, mientras trabajamos predomina los estadios padre y adulto según corresponda, mientras que iniciadas las vacaciones, surge el estadio niño como estructura de comportamiento dominante durante ese tiempo. Sin embargo, el placer no parece ser sólo un elemento presente en los períodos turísticos y Berne, en este punto no explica ni relaciona al placer con el desplazamiento geográfico. Por ese motivo, vamos a descartar (intencionadamente) el desarrollo de la teoría de Análisis Transaccional.

En esta misma línea, Anderson (1972) demostró según un estudio que durante el segundo o tercer año de vida un niño raramente se aleja de su madre más de sesenta metros antes de retornar. Si la pierde de vista, olvida la exploración ya que su deseo es volver con ella. Si el niño es pequeño atraerá la atención "haciendo berrinches" pero si es un niño de más edad emprenderá una búsqueda hasta dar con ella nuevamente. (Anderson, 1972) 
En base a esta observación Bowlby intuye que "podemos entonces dar por sentado que la conducta que lo aleja de su madre hacia el vasto mundo- que se denomina correctamente conducta exploratoria- es incompatible con la conducta de apego y tiene menor prioridad. Así, sólo cuando la conducta de apego está relativamente inactiva, tiene lugar la exploración ... a medida que un individuo se hace mayor, su vida continúa estando organizada del mismo modo, aunque sus excursiones se vuelven continuamente más prolongadas en el tiempo y en el espacio

...Durante la adolescencia pueden durar semanas o meses, y es probable que se busquen nuevas figuras de apego ... todos nosotros, desde la cuna hasta la tumba, somos muy felices cuando la vida está organizada como una serie de excursiones, largas o cortas, desde la base segura proporcionada por nuestra figura de apego." (Bowlby, 1989:78)

En un ensayo teórico publicado en 2007, Korstanje infiere una hipótesis por demás atractiva. Si bien existen ciertas limitaciones metodológicas, es posible que la teoría del apego explique (en parte) la tendencia de ciertas personalidades a recorrer mayores distancias que otras en similitud de condiciones ambientales. Aun cuando, este trabajo no haya sido comprobado en forma empírica (aún) sugiere que las estructuras de apego entre el niño y su cuidador influyen, de alguna u otra manera, en los diferentes procesos en los que se forma la personalidad, y consecuentemente su apego al hogar (base). (Korstanje, 2007)

Sin embargo, la dinámica conductista de la teoría del apego fue seriamente criticada por ciertos sectores conservadores de la psicología tradicional, por considerarla una adaptación ( $\sin$ fundamentos) de la etología (disciplina que le dio nacimiento). (Vemengo, 2005)

En el campo del turismo, un estudio empírico llevado a cabo por White y White (2006) en 27 personas (14 hombres y 13 mujeres) demostró que aquellos quienes se ausentan de su hogar como turistas en lapsos no convencionales (varios meses) tienen una disposición a estar conectados en co-presencia con su hogares, ayudados por los avances tecnológicos en comunicación e informáticos. Aún en las vacaciones, la necesidad de estar ligado a la base segura que representa el hogar y los vínculos emocionales parecen algo ciertamente observable. 
Según la palabra de White y White "these findings are consistent with other work showing that the meaning of distance and being Hawai have tranformed by the ease, immediacy, and frequency of communication between tourist and their families, friend, or colleagues back home. People who are geographically dispersed can now reconstitute and maintain their small social worlds through the use of telephones and the internet”. (White y White, 2007:101)

Otro interesante estudio conducido por Lau y McKercher confirmó que los turistas, una vez en el destino visitado, tienen diversas formas de comportamientos que correlacionan con el tiempo de estadía. Según los autores, en una muestra seleccionada de veraneantes cuyo lapso de estadía es de un máximo de cinco días, se ha observado que entre los días 1 y 5 se realizan mayores visitas a centros cercanos a los hoteles donde se hospedan (como por ejemplo city tours o visita a museos), mientras que entre los días 2, 3, y 4 los turistas se predisponen a explorar otros sitios de mayor distancia geográfica con respecto al lugar donde se alojan. (Lau y Mc Kercher, 2006:48)

Lo cierto, es que la relación entre destino turístico y turista implica conocer la/s causa/s que llevaron a tal acto. Partiendo de la base, de que el turista se desplaza de su medio residencial en busca de la satisfacción de una carencia (Dann, 1981). Algunos investigadores han llegado a proponer dos dimensiones (factores) en los que se desarrolla el fenómeno.

Por un lado, el factor push hace referencia a ciertos los elementos internos e individuales que promueven el movimiento; mientras que por el otro, el factor pull se refiere a las facilidades ambientales externas que posibilitan la atracción. Los motivos específicos que permiten el desplazamiento son variados dependiendo de cada autor y van desde el escape, la necesidad de exploración, hasta la educación y el impulso por la novedad. (Crompton, 1979) (Loker y Perdue, 1992) (Goeldener y otros, 2000) (Castaño y otros, 2006) (Schofield y Thompson, 2007)

Sin embargo, la mayoría de estos trabajos desconoce el papel intra-psíquico que juega el placer y su contrasentido (el no placer) en la disposición del ego para comenzar con el desplazamiento. 
Aun cuando, en ocasiones, alguno que otro autor haga mención sobre el tema, su tratamiento carece de la profundidad necesaria por consecuentemente de operalización y demostración empírica. En este sentido, el psicoanálisis como sub-disciplina propia de la psicología nos presenta un campo fecundo para el estudio del problema. Hasta el momento, el tratamiento sobre el placer, su relación con las dinámicas filo-genéticas y culturales han contribuido notablemente al tratamiento de patologías específicas.

De todos modos, la particularidad que presenta el psicoanálisis como herramienta terapéutica y la dificultad de sus términos, han hecho que pocos investigadores del turismo se dedicaran realmente a profundizar en los factores que generan placer dentro del sujeto. ¿Puede el juego compararse con el placer?

\section{El Juego como objeto transicional}

En su tesis sobre el objeto transicional Winnicott sostuvo que su creatividad, seguridad y estima sobre el self estaría configurada por las posibilidades de desarrollarse durante la etapa de lactante por medio del juego. La ilusión y el objeto transicional se construyen como medios de interacción del ego con su madre. Así, el autor advierte "un niño no tiene la menor posibilidad de pasar del principio del placer al de realidad, o a la identificación primaria y más allá de ella, sino existe una madre lo bastante buena. La "madre" lo bastante buena (que no tiene porque ser la del niño) es la que lleva a cabo la adaptación activa a las necesidades de este y que la disminuye poco a poco, según la creciente capacidad del niño para hacer frente al fracaso en materia de adaptación y para tolerar los resultados de la frustración. ” (Winnicott, 1989:27)

En efecto, el juego (como factor lúdico) se transforma en una experiencia creadora, que vincula al individuo con su ambiente, adaptándolo a superar los obstáculos que éste le presenta. La zona intermedia entre la seguridad materna (cuya expresión podría ser el hogar) y la incertidumbre de un medio (al menos desconocido), deben ser articuladas por un lazo común que puede tomar (según Winnicott) la forma de un objeto transicional.

“La experiencia del bebé con esta confiabilidad a lo largo de un período hace nacer en él, y en el niño en crecimiento, un sentimiento de confianza. La fe del bebé en la confiabilidad de la madre, y por lo tanto en la de otras personas y cosas, permite la 
separación del no-yo y el yo. Pero al mismo tiempo se puede decir que la separación se evita al llenar el espacio potencial con juegos creadores, con el empleo de símbolos y con todo lo que a la larga equivale a una vida cultural”. (Winnicott, 1989: 145)

Nos hemos permitido extendernos, en el desarrollo de esta teoría un poco más de lo normal ya que es de vital interés en el autor, la posición de la cultura como objeto intermedio entre el self y el ambiente. Sin embargo, Winnicott tampoco aclara el rol que juega en este proceso el placer como forma de aprendizaje y consecuentemente como motivo de desplazamiento y búsqueda. El juego parece tener una función de adaptación condicionadamente normada y no hedonista como sugiere el psicoanálisis freudiano, del cual nos ocuparemos a continuación. Pero ¿Por qué Freud y su polémico psicoanálisis?, ¿Qué tiene esta disciplina para aportar al tema estudiado?

\section{El placer y el displacer en Sigmund Freud.}

El psicoanálisis, cabe aclarar, fue creado como forma instrumental para el tratamiento de casos clínicos en parte asociacionista en el sentido indicado por Mead y en parte experimental; pero (por algún u otro motivo) fue rápidamente transformado en un elemento teórico. Parcialmente, heredero de las doctrinas económicas de la prensa hidráulica, las cuales sostenían que ciertos influjos o impulsos actúan por acumulación y una vez sobrepasada la barrera de contención se expresan exteriormente; parte también, producto de una era victoriana con una fuerte regulación de la moral en todas las esferas de la vida cotidiana incluyendo la disciplina y el trabajo. Consideramos, que por estos aspectos, es posible que en Freud el placer halla sido considerado como un aspecto oculto, negativo y sombrío al igual que los diferentes institutos sexuales (todos ellos plausibles de ser re-dirigidos y reprimidos según sus propias palabras). Sin embargo, los alcances freudianos en materia de la relación del sujeto con su entorno y las normas, fue de gran valía para otras disciplinas de las Ciencias Sociales como la Antropología, la Sociología y la Politología.

El mismo Malinowski, corroboró los hallazgos de Freud en las Islas Tobriand donde los nativos se regían por organización matriarcal. Al final de su excelente libro Estudios de Psicología Primitiva, el autor sostiene "nuestro análisis establece que las teorías de Freud no sólo corresponden a la psicología humana en sus rasgos generales, sino que se adaptan estrechamente a las transformaciones que las diferentes formas sociales 
producen en la naturaleza humana. En otras palabras: hemos puesto en evidencia la íntima relación existente entre un señalado tipo de sociedad y su correspondiente complejo nuclear." (Malinowski, 1998: 217

Hechas las pertinentes aclaraciones, nos proponemos a discutir los contenidos, alcances y limitaciones propias del psicoanálisis clásico con referencia al placer y al principio de desplazamiento derivado de éste.

De esta forma, en Más allá del principio del Placer, Freud comienza señalando "en la teoría psicoanalítica suponemos que el curso de los procesos anímicos es regulado automáticamente por el principio del placer; esto es, creemos que dicho curso tiene su origen en una tensión dispaciente y emprende luego una dirección tal, que su último resultado coincide con una minoría de dicha tensión y, por tanto, con un ahorro de displacer a una producción de placer” (Freud, 1988:2508)

Cabe comprender el razonamiento freudiano, dentro del contexto social en el cual éste se desempeñaba. En ese entonces, se creía que los impulsos movían la psicología humana y operaban en analogía a una represa; por acumulación. Cuando cierta cantidad de placer era acumulado, se reducía en el mismo grado la cuota de displacer y viceversa. Las expresiones del agente con respecto a uno $\mathrm{u}$ otro, estaban estrechamente relacionados a como funciona una represa hidráulica.

Al comenzar a estudiar el tema, Freud se topa con una escasa bibliografía en referencia al génesis del placer; en consecuencia la construcción que el psicoanálisis hace sobre el placer obedece, según su autor, a observaciones clínicas directas basadas en las propias experiencias (dinámicas).

En concordancia con otro investigador, que toma como marco referencial ${ }^{4}$, Freud asume que el placer y el displacer están vinculados con los impulsos. Tanto en el polo el placer como su contralor, existe una extensión de indiferencia "estética”. Las dinámicas de uno u otro, se vinculan a su vez, con el equilibrio o la inestabilidad del sistema psíquico. En otras palabras, el principio del placer se deduce por la constancia que conlleva la

\footnotetext{
${ }^{4}$ G. Th. Fletchner. En Algunas ideas sobre la historia de la creación y evolución de los organismos, 1873.
} 
estabilidad del sujeto (postura estática). Pero, el dominio de éste sobre el aparato psíquico es una hipótesis que Freud descarta ya que en la observación empírica no todos los actos del agente llevan al placer. Al respecto el autor sostiene "existe, efectivamente, en el alma fuerte tendencia al principio del placer, pero a esta tendencia se oponen, en cambio otras fuerzas o estados determinados; y de tal manera, que el resultado final no puede corresponder siempre a ella”. (ibid: 2508)

Asimismo, el principio del placer funciona como elemento primario "del aparato anímico" pero es transformado, por los diferentes factores ambientales que lo obligan a retraerse dando lugar (asî) al surgimiento del displacer. El yo asume un instinto de "auto conservación" y el placer puede quedar latente durante un lapso de tiempo manejando los destinos de los "instintos sexuales", mientras es sustituido por "el principio de realidad".

Los mecanismos de represión también ejercen presión sobre los instintos del sujeto, y en ocasiones, se genera lo que Freud llama satisfacción sustitutiva, lo cual implica un sentimiento de displacer. En este sentido el autor afirma "la mayoría del displacer que experimentamos es, ciertamente, displacer de percepción, percepción del esfuerzo de instintos insatisfechos o percepción exterior, ya que por ser esta última penosa, en sí o por excitar en el aparato anímico expectaciones llenas de displacer, y ser reconocida como un peligro por el mismo" (ibid: 2509-10). En consecuencia, reaccionar a estas inspiraciones instintivas y/o de amenaza puede ser dirigida por el principio de realidad directamente hacia el placer.

En una segunda etapa, Freud se decide a analizar el problema desde la óptica lúdica del juego infantil. Más específicamente, el autor interpreta al juego con la cultura y a ésta con la renuncia al propio instinto por medio del proceso de "sublimación". Un niño convierte en un juego, a la vez que placentero, un suceso que por sí mismo es percibido como desagradable (postura dinámica).

En parte, los niños repiten en sus actos lúdicos todo lo que les perturba mientras que por le otro, se asumen en cuanto a un orden jerárquico que les antecede: querer ser como los grandes. Si el sujeto, a temprana edad, sufre una privación (de cualquier naturaleza) está será expresada por medio del juego pero invirtiendo ese displacer (experimentado) en el 
placer de hacerle lo mismo a quien lo ha generado. El origen mismo de la neurosis traumática se basa en el vínculo entre placer y displacer.

En palabras del propio Freud "de toda esta discusión resulta que es innecesaria la hipótesis de un especial institinto de imitación como motivo del juego. Agregaremos tan sólo la indicación de que la imitación y el juego artístico de los adultos, que, a diferencia de los infantiles, van dirigidos hacia los espectadores, no ahorran a estos las impresiones más dolorosas -así en la tragedia-, las cuales, sin embargo, pueden ser sentidas por ellos como un elevado placer. De este modo llegamos a la convicción de que también bajo el dominio del principio del placer existen medios y caminos suficientes para convertir en objeto del recuerdo y de la elaboración psíquica lo desagradable en si”' (ibid: 2513).

Pero lo expuesto hasta el momento, no resuelve ni responde a cuales son los elementos psicológicos que intervienen en el desplazamiento como forma de generar placer.; o en otros términos ¿que placer hay en desplazarse?.

\section{EI desplazamiento}

Curiosamente, Freud no va a hacer referencia exacta a este tema pero nos da algunas pistas. El principio freudiano de equilibrio ante un acto traumático, es la represión y la derivación del hecho al mundo inconsciente. Luego del brote neurótico, el paciente precisamente repite una y otra vez, el trauma recibido. En este punto, Freud no se equivoca cuando asume que la resistencia al análisis por parte del ego viene de la necesidad de ahorrar el displacer (latente, por llamarlo así).

Seguramente, el displacer aumentaría en el mismo grado en que es liberado el recuerdo reprimido. La primera edad sexual genera cierta incompatibilidad de deseos con respecto a la realidad; la pérdida del "amor" y el miedo al abandono sugieren que las vivencias dolorosas sean puestas y repetidas en los procesos de transferencia entre análista y paciente. La proyección derivada sobre el primero, reafirma el lazo de apego con uno de los cuidadores (buena madre en Winnicott) que marcaron la vida psíquica en una edad temprana. En el sentido expuesto, podemos afirmar que el principio de placer y repetición (neurosis) se complementan; más aún es la misma repetición la que conserva el estadio de placer en la estructura psíquica. 
Pero al respecto, Freud es sumamente cauto y advierte "en los juegos infantiles hemos hecho ya resaltar que otras interpretaciones permite su génesis. La obsesión de repetición y la satisfacción instintiva directa y acompañada de placer parecen confundirse aquí en una intima comunidad. Los fenómenos de la transferencia se hallan claramente al servicio de la resistencia por parte del yo, que obstinado en la represión y deseo de no quebrantar el deseo de placer, llama a su auxilio a la obsesión de repetición” (ibid: 2517)

Sin embargo, la misma obsesión debe ser única en su constitución; o por lo menos novedosa. Las manifestaciones repetitivas sólo son placenteras por vez primera, y ello no es casualidad ya que obedece al principio de posesión o dominación. Al respecto señala Freud "cada nueva repetición parece perfeccionar el deseado dominio. También en los sucesos placenteros muestra el niño su ansia de repetición, y permanecerá inflexible en lo que respecta a la identidad de la impresión. Este rasgo del carácter está destinado, más tarde, a desaparecer. Un chiste oído por segunda vez no producirá apenas efecto. Una obra teatral no alcanzará jamás por segunda vez la impresión que en el espectador dejó la vez primera. Rara vez comenzará el adulto la relectura de un libro que le ha gustado mucho inmediatamente después de concluido. La novedad será siempre la condición del goce." (ibid: 2524)

La hostilidad del medio exterior, implica una posición re-activa y adaptativa por parte del sujeto. La novedad, en este sentido, es una manera de poseer o de desear hacerlo. Pero no por ello, se puede afirmar que el motivo del desplazamiento sea el instinto de posesión. Al respecto, Vera Schmitt y Wilhelm Reich aseguraban haber comprobado empíricamente que en las diferentes etapas de maduración del yo en los niños existe una tendencia bien marcada a la posesión, sea éste por aprehensión de objetos (en las etapas inferiores -orales), o por avidez en adquirir conocimiento; pero enseguida estos resultados fueron seriamente cuestionados. (Reich y Schmitt, 1998)

En el organismo se suceden y coexisten dos pulsiones gemelas de la misma intensidad, uno orientado a la vida (sexualidad) llamado eros y otro a la muerte denominado por Freud como thanatos. Dentro de este contexto, el autor en sus conclusiones se cuestiona "es también harto extraño que los instintos de vida sean los que con mayor intensidad 
registra nuestra percepción interna, dado que aparecen como perturbadores y traen incesantemente consigo tensiones cuya descarga es sentida como placer, mientras que los instintos de muerte parecen efectuar silenciosamente su labor. El principio del placer parece hallarse a los servicios de los instintos de muerte, aunque también vigile a las excitaciones exteriores, que son consideradas como un peligro para las dos especies de instintos, pero especialmente a las elevaciones de excitación procedentes del interior, que tienden a dificultar la labor vital”. (Freud, 1988: 2541)

En consecuencia, aún cuando la definición propia de placer en Freud quede inconclusa y difusa, analíticamente se la comprende como aquella descarga que nivela la perturbación sufrida por los instintos de vida (eros) y de muerte (thanatos) en conjunción con la excitación exógena.

En efecto, estas reflexiones son mejor conocidas como la teoría freudiana de las pulsiones, y consiste en el accionar de la líbido (Eros) como una tendencia hacia la vida, mientras que Thanatos representa el impuso destructor o auto-destructor. Ambas fuerzas, pujan durante la vida para "determinar" la evolución del organismo, dando lugar al surgimiento de tres actores en la personalidad, el "yo", el "ello" y el "super yo".

El placer y el principio de realidad operan también como dos elementos fundamentales en la personalidad. Por regla general, tendemos a sentirnos bien y a la búsqueda del placer tratando de disminuir el displacer. Pero por el contrario, el principio de realidad se antepone como el deber que subordina el placer al entorno; lo cual también se conoce como proceso de sublimación, en donde los deseos reprimidos se convierten en energía dentro del sujeto, más precisamente en su inconsciente. El juego, el deporte y el trabajo o más aún las vacaciones no son otra cosa que la sublimación de las propias pulsiones, los cuales en ocasiones pueden expresarse en los procesos oníricos las bromas, los actos fallidos o los sueños entre otros.

A nuestro modo de ver, uno de los autores que mejor resume el pensamiento freudiano es Erich Fromm, quien en su celebre trabajo el Miedo a la Libertad lo como sigue:

"Freud aceptaba la creencia tradicional en una dicotomía básica entre hombre y sociedad, así como la antigua doctrina de la maldad de la naturaleza humana. El 
hombre, según él, es un ser fundamentalmente antisocial. La sociedad debe domesticarlo, concederle unas cuantas satisfacciones directas de aquellos impulsos que, por ser biológicos, no pueden extirparse; pero, en general, la sociedad debe purificar y moderar hábilmente los impulsos básicos del hombre. Como consecuencia de tal represión de los impulsos naturales por parte de la sociedad, ocurre algo milagroso: los impulsos reprimidos se transforman en tendencias que poseen un valor cultural y que, por lo tanto, llegan a constituir la base humana de la cultura" (Fromm, 1987: 31)

En forma crítica podemos señalar (si se quiere), es que para Freud el aparato psíquico se podía comprender como un mercado, en donde diversas pulsiones se intercambian unas a otras obteniendo a su favor ciertas satisfacciones en detrimento de ciertas privaciones. Por el contrario, para Fromm las dinámicas acaecidas de los organismos humanos no obedecen a leyes o mecanismos intrapsiquícos o biológicos sino a procesos culturales más extensos y complejos a lo que llegó a mencionar su maestro; aun cuando comparte con éste ciertos postulados en cuanto a la neurosis. Para ser más exactos, al igual que Freud, Fromm está convencido que la dinámica de la adaptación neurótica, tema de cual ya nos hemos ocupado. ${ }^{5}$

\section{CONCLUSIONES}

Todo lo expuesto hasta el momento, nos autoriza (en forma tentativa) a ir diagramando la explicación y los aportes freudianos en cuanto al placer y su relación con el desplazamiento geográfico.

En analogía, a la transferencia (que en sí es una forma de desplazamiento) podemos señalar que existen en el sujeto mecanismos internos denominados pulsiones que al

\footnotetext{
${ }^{5}$ Explicado por Fromm de la siguiente forma: "nos parece útil distinguir entre adaptación estática y la dinámica. Por la primera entendemos una forma de adaptación a las normas que deje inalterada toda estructura del carácter e implique la adopción de un nuevo hábito ... un ejemplo de este tipo de adaptación lo constituye el abandono de la costumbre china en las maneras de comer a cambio de la europea, que requiere el uso de tenedor y cuchillo. Un chino que llegue a América se adaptará a esta nueva norma, pero tal adaptación tendrá en sí misma un débil efecto sobre su personalidad... por adaptación dinámica entendemos aquella especie de adaptación que ocurre, por ejemplo, cuando un niño, sometiéndose a las ordenes de un padre severo y amenazador - porque lo teme demasiado para proceder de otra manera-, se transforma en un buen chico. Puede desarrollar una intensa hostilidad hacia su padre, y reprimirla, puesto que sería demasiado peligroso expresarla o aun tener conciencia de ella. Tal hostilidad reprimida, sin embargo, constituye un factor dinámico de la estructura de su carácter”. (Fromm, 1989:36)
} 
chocar (inevitablemente) con la represión del medio externo, se generan pequeños traumas que causan displacer. Estos hechos, son expresados desde la esfera lúdica invirtiendo su estructura y generador; así surge lo que conocemos como principio de repetición o neurosis. A su vez, y en una última etapa, el sistema psíquico genera gran cantidad de energía en mantener el equilibrio propio. En consecuencia, cualquier acto externo al individuo para rememorar el trauma genera un proceso de transferencia o proyección (defensivo) que tiende a mantener al displacer latente. La transferencia pero más precisamente el movimiento, y con él seguramente el desplazamiento físico, generan estabilidad (placer) que sólo puede ser sustituido por el principio de realidad como mencionaron tanto Freud como Winnicott.

Este sería el motivo o la causa por la cual el desplazamiento geográfico también funciona como un elemento generador de placer en el sujeto; o en su defecto reductor del displacer. Tanto un inmigrante, que decide abandonar su medio debido a las constante privaciones que percibe como también un turista quien tras el agobio y las restricciones sufridas en su esfera laboral inicia un proceso de proyección de sus propios deseos (hedonistas) en sus vacaciones.

Es sobre todo durante el receso de vacaciones, que los sujetos intentan hacer todas aquellas cosas que no pudieron durante el año pero las cuales no son tan diferentes en comparación. Es decir, podemos elegir un destino alejado de aquella ciudad en la cual vivimos, incluso optamos por un programa en el cual se contemplen actividades nuevas, pero siempre dentro de una lógica de repetición (obsesiva) que invierte la posición del sujeto.

Así, como el niño por medio del juego regula su displacer generando el mismo daño que recibe, también el turismo quien por regla en su cotidianeidad es subordinado a un superior, en su receso exige subordinación y servicio.

En definitiva, como señala el profesor Freud, un acto reproduce a otro cíclicamente (una y otra vez). Para que la rotura de ese círculo, no cause un desequilibrio o displacer en el sujeto (en el caso de estar desempleado o fuera del sistema laboral), se forma en el desplazamiento (transferencia) un mecanismo cuya función es la preservación del placer en la vida del sujeto. 
Esta naturaleza cíclica del desplazamiento y en comparación de la neurosis, tiene cierta analogía con la dinámica del mito (sino casi la misma). Pero ese parece un interesante punto de estudio, esperándonos para otro ensayo. En este sentido, es conveniente preguntarse ¿cuáles son las influencias de la mitología judeo-cristiana en la lógica del los desplazamientos voluntarios llamados turísticos?.

\section{REFERENCIAS BIBLIOGRAFICAS}

Anderson J.W. (1972). “Attachment Behaviour out of Doors". Cambridge University Press, Cambridge.

Blanco, Albert. (2001). Turismo y Transporte. Madrid: Editorial Síntesis.

Berne, E. (1974). Los Juegos en que participamos. México: Editorial Diana.

Bowlby, J. (1989). Una Base Segura: aplicaciones clínicas de la teoría del apego. Buenos Aires: Editorial Paidos.

Castaño, J.M y otros. (2006). "Factores psicosociales y formación de imágenes en el turismo urbano: un estudio de caso sobre Madrid". Revista Pasos, volumen 4, número 3. Pp. 287-799.

Crompton, J. (1979). "Motivation for pleasure travel". Annals of Tourism Research, volumen 6, número 4. Pp.: 408-424.

Dann, G. (1981). "Tourist motivation: an appraisal". Annals of Tourism Research, volumen 8, número 2. Pp: 187-219.

Eriksson, Erik. (2000). Ciclo Vital completado. Barcelona: Editorial Paidos.

Fernández Fuster, Luís. (1967). Teoría y Técnica del Turismo. Madrid: Editora Nacional. 
Freud, Sigmund. (1988). Freud: obras completas. Volumen XIII. "Más allá del principio del placer”. Pp.: 2507-2541. Buenos Aires: Editorial Hyspamerica.

Fromm, Erich. (1987). El Miedo a la libertad. Buenos Aires: Editorial Paidos.

Goeldene, CR y otros. (2000). Tourism principes, practices and philosophies. Nueva York: Wiley Ed.

Kant, Immanuel. (2004). Crítica de la Razón Pura. Buenos Aires: Ediciones Libertador.

Korstanje, M. (2007). “Aplicaciones de la teoría del apego en el turismo: crítica a la teoría de la base segura”. Revista Internacional de Psicología. Instituto de la Familia, Guatemala, volumen 62.

Lau, G. y McKercher, B. (2006). "Understanding tourist movement patterns in a destination: a Gis approach". Tourism and Hospitality Research, Volumen 7, Número 1. Pp.:39-49.

Loker, L y Perdue, R. (1992). “A Benedit-based segmentation of a non-resident summer travel market”. Journal of Travel Research, volumen 31, numero 1. Pp.: 30-35.

Malinowski, Bronislaw. (1998). Estudios de Psicología Primitiva. Barcelona: Editorial Altaya.

Mead, G. H. (1999). Espíritu, persona y sociedad. Barcelona: Editorial Paidos.

Reich, Wilhelm y Scmitt, Vera. (1998). Psicoanálisis y Educación. Buenos Aires: Atalaya Editorial. 
Schofield, P y Thompson, K. (2007). "Visitor motivation, satisfaction and behavioural intention: the 2005 Naadam festival. Ulaanbaatar". International Journal of Tourism Research, volumen 9. Pp.: 329-344.

Vemengo P. (2005). “Apego”. Revista Psicoanálisis Hoy, volumen 4. Pp.: 1-4

Vleeschauwer, J.H. (2002). "Kant”. En Belaval Y. La Filosofía Alemana de Leibniz a Hegel. Buenos Aires: Siglo XXI.

White, R. N. y White, P. B. (2007). "Home and away: tourists in a connected world". Annals of Tourism Research, volumen 34, número 1. Pp. 88-104.

Winnicott, D. (1989). Realidad y Juego. Barcelona: Editorial Gedisa.

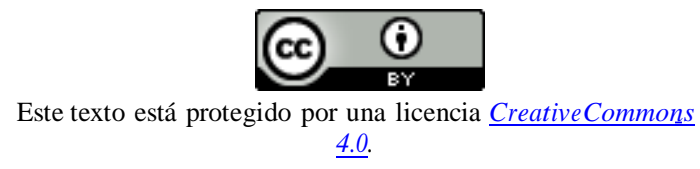

Usted es libre para Compartir — copiar y redistribuir el material en cualquier medio o formato - y Adaptar el documen- to - remezclar, transformar y crear a partir del material- para cualquier propósito, incluso comercialmente, siempre que cumpla la condición de:

Atribución: Usted debe reconocer el crédito de una obra de manera adecuada, proporcionar un enlace a la licencia, e in- dicar si se han realizado cambios. Puede hacerlo en cualquier forma razonable, pero no de forma tal que sugiera que tie- ne el apoyo del licenciante o lo recibe por el uso que hace. 